\title{
MANAGEMENT OF INTRAVENOUS THERAPY IN GENERAL WARDS OF A LARGE TEACHING HOSPITAL
}

\author{
U. Brinkcate and D. Lee
}

\section{INTRODUCTION}

"Although the basic idea is more than $\mathbf{3 0 0}$ years old, intravascular therapy did not become widely accepted until the 1920's when a way was found to rid intravenous fluids of pyrogens.... Today, more than $25 \%$ of all patients receive some form of intravascular therapy during hospitalization,.... Although the nurse doesn't necessarily insert all types of intravascular lines, she is responsible for maintaining these lines and preventing complications throughout the patient's therapy." (Hamilton, 1983). She is responsible too, for monitoring the solutions, maintaining flow rates and ensuring the patient's safety and comfort during I.V. therapy (Lewis, 1984). These principles motivated the researchers to undertake a study to determine how intravenous therapy is managed in medical wards, with special note being made of the magement of flow rate, changing of vacolitres and the management of blockages. The researchers felt that such information would help clinical staff develop appropriate protocols for the management of intravenous therapy.

Research problem: There were inadequate protocols for the management of intravenous therapy in areas where the researchers had worked, leaving the management of I.V. therapy open to misinterpretation.

The research question which developed from this observation was: "How do nursing staff in medical wards manage and monitor inuravenous therapy over an 18 hour period?"

In order to answer this question the following objectives were drawn up:

1. To assess methods of measuring flow rate.

2. To obtain information relating to the technique being used for changing of vacolitres

3. To ascertain the methods being used for the unblocking of intravenous lines.

4. To discover if charting of intravenous therapy is being done.

\section{Abstract}

The monitoring of intravenous therapy by nursing staff in medical wards over an 18 hour period was studied.

The study focused on the measuring or flow rates, the rechnique used for unblocking intravenous lines and how recording was managed. Only intravenous therapy which was likely to be in situ for longer than a 24 hour period was studied in randomly selected medical wards.

Procedures were carried out by all categories of staff. Although timing devices were used for flaw rates they were still incorrect. A need for improved recording was established and no clearly defined methods for unblocking intravenous lines were found.

\section{DEFINITIONS OF TERMS USED IN TIIIS STUDY}

Intravenous therapy: the insertion of a cannula into a peripheral vein for the replacement of fluid. For the purposes of this study parenteral nutrition, intravenous blood transfusions or central, long and subclavian lines are not included.

Sterile manner: The prevention of contamination of the ends of the vacolitre or administration set.

Timing device: a stop, wrist or fob watch with a second hand.

Blockage: an obstruction to the flow of the intravenous fluid which many take the form of air, kinks in the tubing, blood or extravasation.

Prescribed flow rate: the number of drops per minute at which the intravenous therapy should run. It is prescribed by a medical officer, and is calculated using the following formula:-

\section{Drops per minute $=$ \\ Total volume infused $x$ drops per millilitre \\ Total time for infusion in minutes}

\section{METIIODOLOGY}

Research Design

Descriptive observational study.

\section{Population}

This consisted of all adult patients in 14 medical wards who were receiving intravenous therapy for a period of not less than 24 hours. The management of intravenous therapy "to keep vein open", is not standardised, and for this reason these patients were excluded.

\section{Sample}

A random sample of 5 medical wards was chosen for this study. Medical wards were chosen because it was noted that intravenous therapy was more likely to be in situ for a period longer than 24 hours. To have monitored intravenous therapy in specialist wards would have increased the number of variables.

\section{Research Tool}

An observational checklist was designed in order to gather data relating to:

1. Flow rate of intravenous therapy.

2. Changing vacolitres.

3. Management of blockages.

Pilot Study

A pilot study was conducted in order to check the face and content validity of the checklist.

Data Collection Procedures and Findings A time table was drawn up that ensured two researchers were in the ward for a period of two hours throughout the eighteen hour period. In this way procedural interventions were able to be evaluated.

Referring to Figure 1 , it is seen that in the majority of observations made, the procedure was carried out by enrolled nurses. In $6 \%$ of the observations, the management of intravenous 
KEV:

$\mathrm{P} V \mathrm{~N}=$ Registered Nurse

ENA = Enrolled Nursing Assistant

$\mathrm{ST} / \mathrm{N}=$ Student Nurse

$E / N=$ Enrolled Nurse

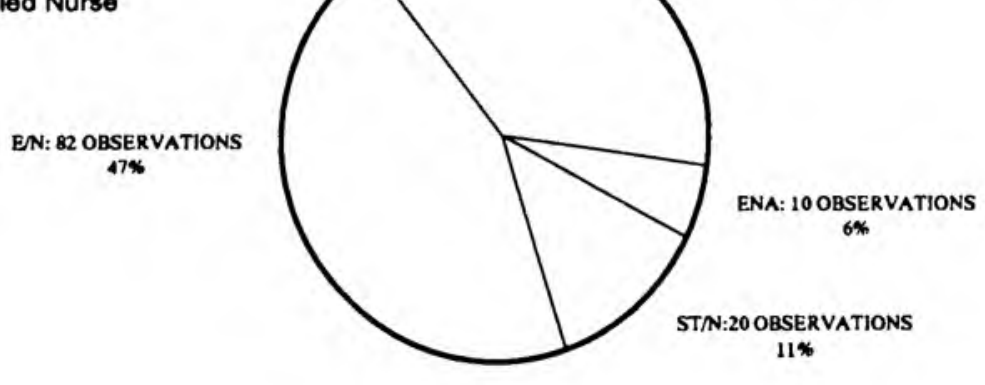

Figure 1

Number of observations carried out by different categories of staff $n=174$

therapy was carried out by enrolled nursing assistants. This is an area of concern because according to the hospital policy, nursing assistants may not administer intravenous injections or manage intravenous therapy.

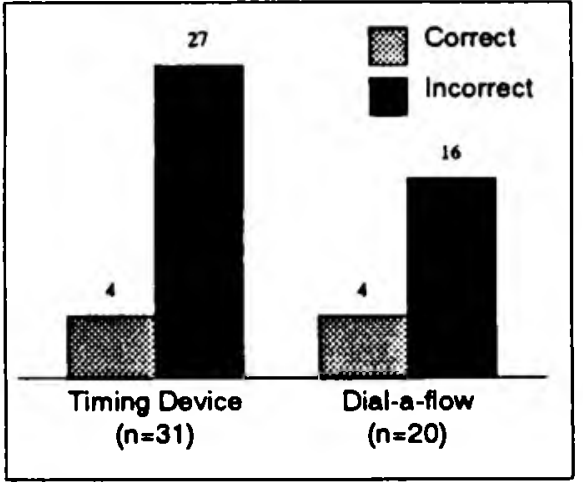

Flgure 2

Methods of checking intravenous therapy flow rates $n=51$
In Figure 2, it can be seen that 4 of 31 intravenous flow rates $(12,9 \%)$ were calculated correctly when a timing device and the calculation for determining the prescribed flow rate were used; 4 of the $20,(20 \%)$ intravenous flow rates measured using a dial-a-flow method were correct. The researchers found that although a dial-a-flow was in situ, intravenous flow rates were also being regulated by means of the clamp on the administration set, thereby altering the flow rate controlled by the dial-a-flow. In fact, $84 \%$ of the flow rates were calculated incorreclly.

Bars B to E of Figure 3 show that the majority of vacolitre changes were performed according to the stated criteria. The researchers query the sterility of the procedure as in only $3(4 \%)$ of 82 vacolitre changes observed was hand-washing performed before changing the vacolitre. This poses a question as to whether hand-washing prior to vacolitre changing is a criterion for correct management, or should the question of washing hands be stipulated only when dealing with the actual needle and needle site?

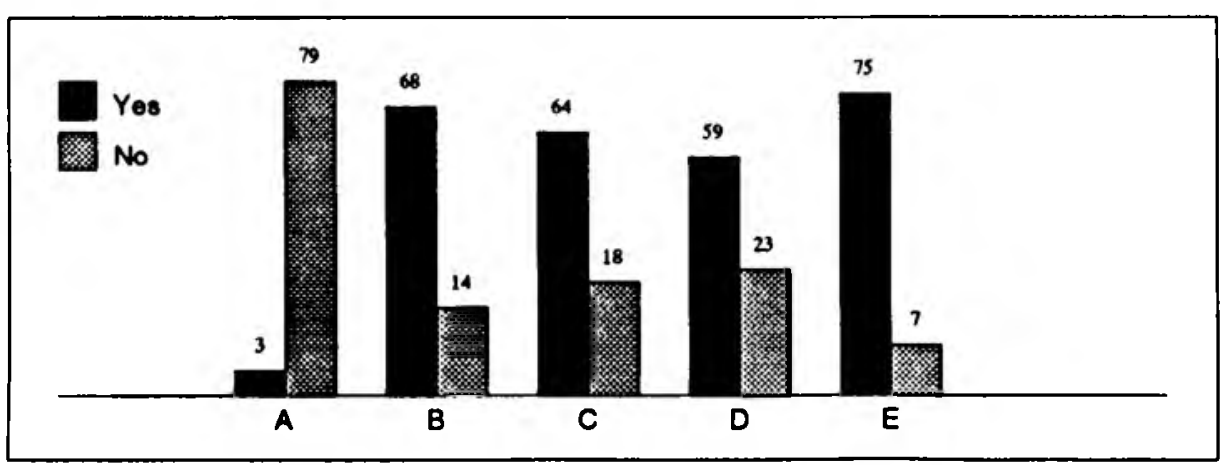

Figure 3

Malntenance of aterility when changing vacolitres $n=82$

\section{KEY - Did the nuree:}

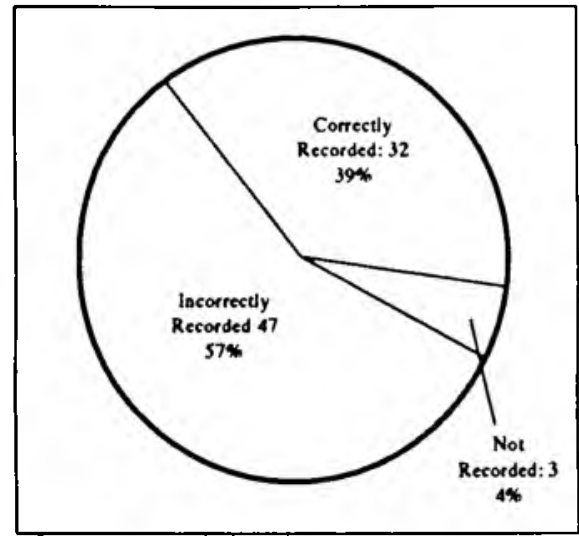

Figure 4

Pecording of vacolitre changes $n=82$

Maintenance of haemodynamic status is crucial to management of certain medical diagnoses, therefore meticulous charting of intravenous therapy is mandatory.

Figure 4 shows that less than half vacolitre changes were recorded correctly - $32(39 \%)$ of 82 changes - on the Balfec (Intake and Output) Chart. Further, in order to maintain the correct amount being given to the patient, the flow rates need to be regul ated after each vacolitre change. The flow chart in Figure 5 shows the sequence of events after each vacolitre change. It should be noted that only 15 of the 82 vacolitres that were changed had flow rates which werc checked and correct at the end of the procedure.

The methods found to be in use for unblocking intravenous lines were:

1. Withdrawal of fluid from nubber bung using a syringe.

2. Positional changes.

3. Removal of air by pencil technique and withdrawal of air via rubber bung.

The above methods have been described by Hirsh \& Hancock (1981) and Brunner \& Suddarth (1986), and were not part of the hospital protocol for managing I.V. therapy. The method of removing either air or fluid from the rubber bung is controversial, because of the danger of introducing infection into the I.V. fluid and into the venous site. Of concern is how many holes a rubber bung can sustain before its integrity is compromised? This method was used in 10 of the 13 observed air blockages. Further, it is of importance to note that of the 82 observations there were 61 blockages. (Fig.5)

Figure 6 illustrates the four distinct types of blockages observed by the researchers. These were:

1. Extravasation of intravenous fluid into the surrounding tissue $(27,9 \%)$.

2. Blood clots in the intravenous cannula $(24,6 \%)$. 


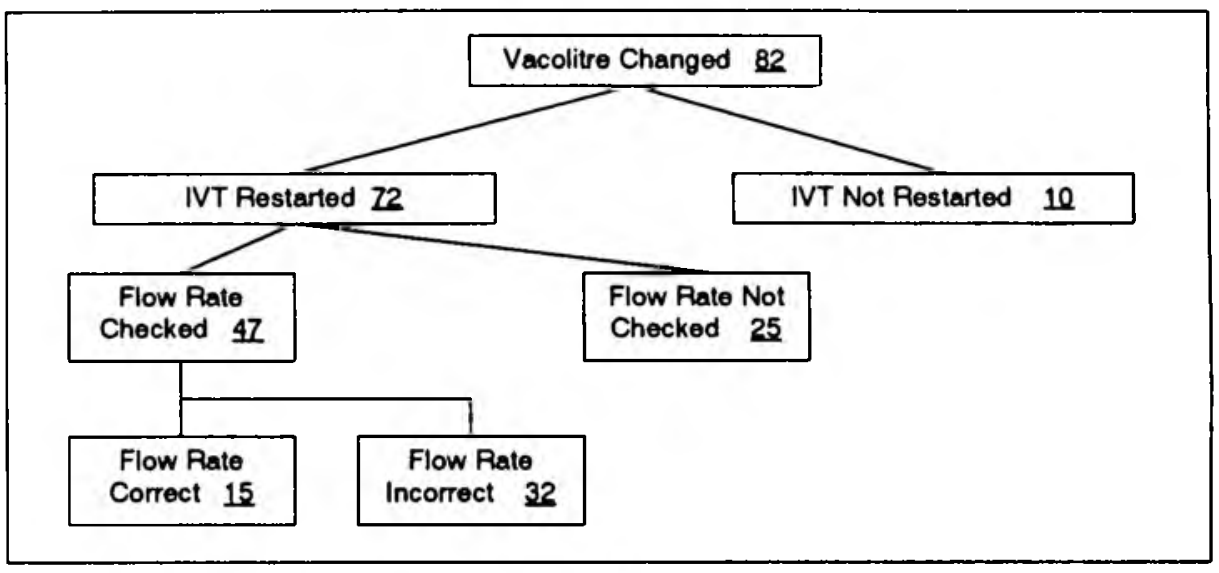

\section{Figure 5}

Checking of flow rate after changing of vacolitres

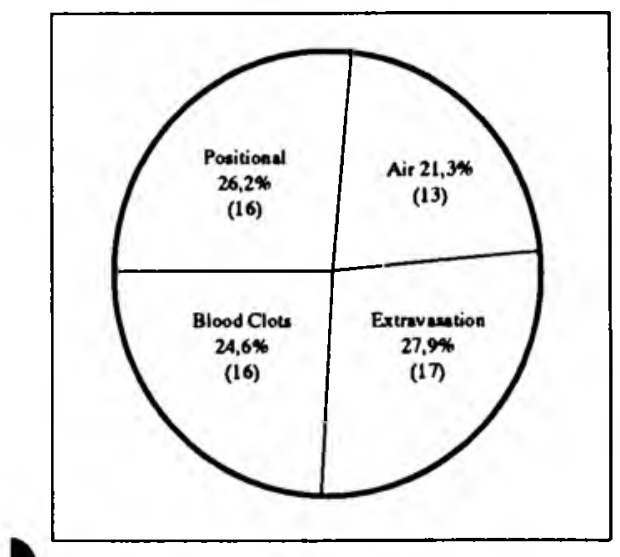

\section{Figure 6 \\ Types of blockages observed $n=61$}

3. Blockages due to position of the limb in which the intravenous therapy is sited (26,2\%).

4. Air in the administration line $(21,3 \%)$.

The following is a brief description of the findings in regard to management of blockages.

\section{Management of intravenous therapy in tissue}

When an intravenous cannula pierces the wall of a vein, it must be removed to prevent infiltration of fluid into the tissues which may cause discomfort to the patient, or cellulitis. Before removing the intravenous equipment a student nurse, enrolled nurse or enrolled nursing assistant must report this to a registered nurse. The researchers found that $8(47 \%)$ of 17 of the observed intravenous infusions that had infiltrated the tissues were not reported to a registered nurse before being removed.

2. Management of blockages caused by blood clots is as follows:

- The intravenous therapy is turned off using the clamp on the administration set.
- This study showed that in 14 of the 15 observations made the intravenous therapy was lumed off.

- Cleaning of the rubber bung with an alcohol swab.

- This was performed in $6(40 \%)$ of 15 observed blockages.

- A needle and syringe are inserted into the rubber bung and fluid is withdrawn. The clot is withdrawn thereby into the syringe preventing it from being dislodged, entering the vein and causing an embolus.

- This was done in 6 of the 15 observations.

- If this is not successful and the intravenous line is still blocked it should be removed. - In 2 of the 15 observations the intravenous line was removed or the situation reported to a registered nurse.

Further analysis of the data showed that in only $3(20 \%)$ of the 15 observations was the procedure of removing a blood clot from an intravenous cannula performed correctly. This excludes the recording of the procedure which was not done in these three cases.

\section{Positional Blockages}

Positional blockages occur when blood flow through a vein is stopped because the position of the limb results in kinking of the intravenous cannula or compression of the vein. The findings of this study showed that $4(25 \%)$ of 16 positional blockages were corrected by splinting the limb. In the remaining 12 observations no action was taken to correct the blockage.

\section{Removal of air from intravenous} administration lines can be done by using either the "pencil" technique or the "needle" technique.

Pencil technique was used correctly in 3 of the 13 cases where air was removed from an intravenous line. This technique involves the moving of the plastic drip regulator down the administration set until it is well below the level of air in the set, and it is turned off. A pen, pencil or syringe is then placed next to the regulator on the side of the air. The tubing is rolled tightly around the syringe or pen, displacing the air and fluid towards the vacolitre. When the last of the air has passed retrogradely back through the filter, the tubing is released from the pen or syringe and it fills with fluid from the container.

Needle technique was used in 10 of the 13 cases. The following steps are used in this technique:

* * The intravenous therapy is turned off when air is noticed in the administration set.

- The rubber bung is cleaned with an alcohol swab.

* The intravenous line is turned on and air is allowed to run closer to the bung.

- A needle is inserted into the rubber bung and the air is allowed to run out.

- The needle is removed once the air has run through.

- The needle is disposed of in a "sharps" container.

In the 10 observations made of the needle technique for removing air from an administration set, the majority were not carried out in the prescribed manner.

\section{CONCLUSION}

Intravenous therapy is used frequently in hospitalized patients and nurses play a major role in the maintenance of intravenous lines and preventing complications of intravenous therapy. This study highlights the fact that there is no standardized method for unblocking intravenous lines. There is a standardized method of changing vacolitres, but flow rates and recording of fluids infused are areas of management of I.V. therapy which need focus and clarification.

\section{AREAS FOR FURTIIER RESEARCII}

1. Does hand washing affect sterility when managing intravenous therapy?

In this study only 3 of 82 staff observed washed their hands before changing a vacolitre.

2. Research into the validity and effectiveness of a new protocol for the management of intravenous therapy once it is instituted.

3. The management of the following specialized forms of intravenous therapy such as Total Parenteral Nutrition, giving of blood products, Hickman and central lines.

\section{REFERENCES}

BAR, Z.V. 1984. Getting air out of the IV line. Canadian Medical Association Journal. Sepı. 15; 131(6), 539. 
BARRUS, D.H. AND DANEK, G. 1987. Should you irrigate an occluded IV line? Nursing 87, March; 17(3), 63-4.

BRITTEN, J.D. AND PRIEST, M.A. 1979. Practical Notes on Nursing Procedures. 7th Ed. Edinburgh: Churchill Livingstone.

BOYKOFF, S.L., BOXWELL, A.O. AND BOXWELL, JJ. 1988. 6 Ways to clear the air from an IV line. Nursing 88 February $18(2), 46-48$.

BRUNNER, L.S. AND SUDDARTH, D.S. 1986. The Lippincont Manual of Nursing Practice. 4th Ed. Philadelphia: Lippinoott.

CLARKE, M. 1977. Practical Nursing. London: Baillieré Tindall.

DU GAS, B.W. 1983. Introduction to Patient Care. A Comprehensive Approach to Nursing. 4th Ed. Philadelphia: W.B. Saunders.

ELLIS, J.R. KNOWLIS, E.A. AND BENTZ, P.M. 1980. Modules for Basic Nursing Skills, Vol. 2, 2nd Ed. Boston: Houghton Mifflin.

ERB, G. AND KOZIER, B. 1987. Techuiques in Clinical Nursing: A Nursing Process Approach. 2nd Ed. Menlo Park: Addison Wesley.

HAMILTON, H.K. Ed. 1983. Procedures. The Nurses Reference Library. Springhouse $\mathrm{Pa}$. Intermed Communication Inc.
HIRSCH, J. AND HANCOCK, L. Ed. 1981. Mosby's Manual of Clinical Nursing Procedures. St. Louis: C.V. Mosby

LEWIS, L.W. 1984. Fundamental Skills in Patient Care. 3rd Ed. Philadelphia: J.B. Lippincolt.

MACRAE, S., SCHOLES, M.E. AND WILSON, J.L. 1982. Handbook of Nursing Procedures. Edinburgh: Blackwell Scientific Publications.

MILLAM, D.A. 1988. Managing Complications of IV Therapy. Nursing 88 March 8(3), 34-42.

MILLAM, D.A. 1988. Are Nurses Prepared to Perform IV Therapy. Nursing 88 August 18(8), 43.

MULDER, M. AND NOWLAN, G. 1986 Practical Guide for General Nursing Science. Pretoria: Haum Educational Publishers.

NELSON, R. AND MILLER, H. 1986. Keeping air out of IV lines. Nursing 86 March 16(3), 57-59.

POLIT, D. AND HUNGLER, B. 1983. Nursing Research-Principles and Methods. 2nd Ed. Philadel phia: J.B. Lippincott.

RYKHEER, G.M. 1973. Modern Clinical Nursing and Applied Sciences. Pretoria: G.M. Rykheer Publishers.

SCHAFER, et al 1975. Medical-Surgical Nursing. 6th Ed. St. Louis: C.V. Mosby
STEEL, J. 1983. Too Fast or Too Slow - The Erratic IV. American Journal of Nursing June 83(6), 898-901.

TREECE, C.W. AND TREECE, J.W. 1986. Elements of Research in Nursing. St. Louis: C.V. Mosby

VLOK, M.E. AND LOCHNER, M.M.M. 1980. Manual of Basic Nursing. 8th Ed. Cape Town: Juta \& Co.

JOHANNESBURG HOSPITAL: Intravenous Infusions and Introduction of Additives Therein. Standing Orders Patient Care No. 7. Hospital No. $3 / 59$

\section{FINAL YEAR NURSING UNDERGRADUATES INVOLVED IN TIIE RESEARCII}

Rae Backman, Claire Boulanger, Tracey Hancock, Bundy Hobson, Robyn Holgate, Maia Jeannot, Fiona Johnston, Emmanual Komoreng, Jackie Moshe, Anthea Neilson, Vanessa Pellatt, Anthea Rachelson, Elijah Sibeko, Fiona Storer, Colleen Townsend and Sally Tustin.

U. Brinkcate

BN (Witwatersrand) RN. RM. RPN. CHN. D. Lee

BA(Cur)(UNISA), MSr(Nursing), DNED (Witwatersrand) RN. RM. RT. CHN. RNA.

Department of Nursing Education University of Witwatersrand 